\title{
Impact of GOLD groups of chronic pulmonary obstructive disease on surgical complications
}

\author{
This article was published in the following Dove Press journal: \\ International Journal of COPD \\ 10 February 2016 \\ Number of times this article has been viewed
}

\author{
Hyung-Jun Kim ${ }^{1,2}$ \\ Jinwoo Lee ${ }^{1,2}$ \\ Young Sik Park ${ }^{1,2}$ \\ Chang-Hoon Lee ${ }^{1,2}$ \\ Sang-Min Lee ${ }^{1,2}$ \\ Jae-Joon Yim ${ }^{1,2}$ \\ Chul-Gyu Yoo',2 \\ Young Whan Kim ${ }^{1,2}$ \\ Sung Koo Han ${ }^{1,2}$ \\ Sun Mi Choi ${ }^{1,2}$
}

'Division of Pulmonary and Critical Care Medicine, Department of Internal Medicine, Seoul National University Hospital, Seoul, Republic of Korea; ${ }^{2}$ Department of Internal Medicine, Seoul National University College of Medicine, Seoul, Republic of Korea
Correspondence: Sun Mi Choi Division of Pulmonary and Critical Care Medicine, Department of Internal Medicine, Seoul National University College of Medicine, Seoul National University Hospital, I0I Daehak-Ro Jongno-Gu, Seoul I I0-744, Republic of Korea

Tel +82 220724915

Fax +8227629662

Email sunmich8I@gmail.com
Purpose: Chronic obstructive pulmonary disease (COPD) is associated with increased postoperative complications. Recently, the Global Initiative for Chronic Obstructive Lung Disease (GOLD) classified COPD patients into four groups based on spirometry results and the severity of symptoms. The objective of this study was to evaluate the impact of GOLD groups on postoperative complications.

Patients and methods: We reviewed the medical records of COPD patients who underwent preoperative spirometry between April and August 2013 at a tertiary hospital in Korea. We divided the patients into GOLD groups according to the results of spirometry and self-administered questionnaires that assessed the symptom severity and exacerbation history. GOLD groups, demographic characteristics, and operative conditions were analyzed.

Results: Among a total of 405 COPD patients, 70 (17.3\%) patients experienced various postoperative complications, including infection, wound, or pulmonary complications. Thoracic surgery, upper abdominal surgery, general anesthesia, large estimated blood loss during surgery, and longer anesthesia time were significant risk factors for postoperative complications. Patients in high-risk group (GOLD groups C or D) had an increased risk of postoperative complications compared to those in low-risk group (GOLD groups A or B).

Conclusion: COPD patients in GOLD groups representing a high exacerbation risk have an increased risk of postoperative complications compared to those with low risk.

Keywords: chronic obstructive pulmonary disease, dyspnea, postoperative complications, risk assessment, spirometry

\section{Introduction}

Chronic obstructive pulmonary disease (COPD) is a disabling disease, of which the prevalence increases with age and causes significant morbidity and mortality. ${ }^{1}$ It is the ninth leading cause of years of life lost according to World Health Organization Global Health Observatory data (http://www.who.int/gho/en/).

In the previous version of the Global Initiative for Chronic Obstructive Lung Disease (GOLD) guidelines, classification of COPD was based only on the forced expiratory volume in 1 second $\left(\mathrm{FEV}_{1}\right)$. In 2011, the GOLD guidelines emphasized the use of a combined COPD assessment based on exacerbation risk and patient symptoms, and a new classification of GOLD groups was suggested (http://www.goldcopd.com/). In recent studies, the capacity of this new COPD classification for predicting the clinical course of COPD has varied..$^{2-4}$

As the numbers of COPD patients increase with longer life expectancy, more surgeons encounter surgical patients with underlying COPD. It is known that COPD is an independent risk factor for increased postoperative morbidity, mortality, and length of hospital stay. ${ }^{5}$ It has been reported previously that such morbidities not only 
include postoperative pulmonary complications, but also wound dehiscence, sepsis, and cardiac and renal complications. Therefore, accurate assessment of the status of COPD patients is important for guiding appropriate perioperative management.

To the best of our knowledge, the relationship between the COPD GOLD group and postoperative complications has not yet been studied. The aim of this study was to evaluate whether the COPD GOLD group classification is associated with the rate and type of postoperative complications.

\section{Material and methods}

\section{Study design}

We reviewed the medical records of COPD patients detected by preoperative spirometry at Seoul National University Hospital, between April 2013 and August 2013. This study was conducted in accordance with the amended Declaration of Helsinki, and was reviewed by the institutional review board at Seoul National University Hospital (protocol number H-1403-102-567, approval date April 22, 2014). During this period, self-administered questionnaires were collected in the pulmonary function test room of the hospital. Informed consent requirement was waived due to the retrospective study design, but patient records and information was anonymized and deidentified prior to analysis. Questions included those on comorbidities and the level of dyspnea (assessed using the COPD assessment test [CAT] and modified medical research scale [mMRC]). Details of the collection of COPD diagnostics have been described in our previous report in which we evaluated the prevalence of COPD among surgical candidates. ${ }^{6}$ The data collected included demographic characteristics, comorbidities, spirometry results, operative conditions such as anesthesia time and estimated blood loss (EBL), and type of postoperative complications that occurred.

\section{Definition}

We defined COPD as a postbronchodilator $\mathrm{FEV}_{1} / \mathrm{FVC}$ (forced vital capacity) ratio of $<0.7$ in patients $\geq 40$ years of age. The COPD patients were classified into four groups according to the revised GOLD guidelines, based on the results of spirometry, symptom severity, and history of acute exacerbation reported on the questionnaire.

Postoperative complications were defined as any deviation from the normal postoperative course, which included pulmonary, cardiac, infection, wound, and other complications. ${ }^{7}$ Pneumonia was diagnosed based on typical clinical features (cough, fever, sputum production, or pleuritic chest pain), imaging findings, and laboratory results such as leukocytosis and elevated C-reactive protein levels. ${ }^{8,9}$ Wound complications were divided into major (Grades III and IV) and minor (Grades I and II) complications, according to whether further mechanical interventions were required such as drainage insertion or reoperation. ${ }^{7}$

\section{Statistical analysis}

Statistical analyses were performed using SPSS 22.0 (IBM Corporation, Armonk, NY, USA). Variables were compared between patients with and without postoperative complications using the Pearson $\chi^{2}$ or Fisher's exact tests for categorical variables, and the Student's $t$ - or Mann-Whitney $U$-tests for continuous variables in univariate analyses. Multivariate analysis using binary logistic regression was performed to evaluate factors related to postoperative complications.

\section{Results}

\section{Baseline characteristics}

A total of 474 COPD patients underwent preoperative spirometry. Among them, 69 patients did not undergo surgery for nonmedical reasons. Consequently, 405 patients were included in this study.

Of the 405 patients who underwent surgery, 58.7\% were male, with a median age of 70 (range: 44-91) years. The overall body mass index (BMI) was $23.33 \pm 2.98 \mathrm{~kg} / \mathrm{m}^{2}$. Distribution of the GOLD groups was as follows: $62 \%$ $(n=251)$ fell in group A, 32\% $(n=130)$ in group $B, 3 \%(n=11)$ in group $C$, and $3 \%(n=13)$ in group $D$. The most common comorbidities were malignancy (51\%), hypertension (51\%), diabetes mellitus (19\%), and cardiac diseases (13\%) such as heart failure, angina, or arrhythmia (Table 1). Genitourinary (25\%), upper abdominal (21\%), and orthopedic operations $(13 \%)$ were the most frequently performed surgeries.

\section{Postoperative complications}

Approximately $17.3 \%(n=70)$ of the patients experienced complications after surgery. The most common were infections (31\%), wound (38\%), and pulmonary complications (29\%). Among the 22 patients who developed infectious complications, three patients had bloodstream infections and one had septic shock. Postoperative wound complications included wound dehiscence, seromas, intracavitary fluid collections, and superficial wound infections. Of the 27 patients with such complications, 17 (63.0\%) had major complications that required further surgical or angiographic intervention. Pneumonia was the most common pulmonary complication, followed by pleural effusion and atelectasis (Table 2). No mortality was observed during hospitalization. 
Table I Baseline characteristics of study patients

\begin{tabular}{|c|c|c|c|}
\hline Variables & $\begin{array}{l}\text { Patients without } \\
\text { postoperative } \\
\text { complications, } \\
n=335\end{array}$ & $\begin{array}{l}\text { Patients with } \\
\text { postoperative } \\
\text { complications, } \\
n=70\end{array}$ & $P$-value \\
\hline$\overline{A g e^{a}}$ & 70 (46-9I) & 71 (44-88) & 0.841 \\
\hline Male sex & 281 (83.9) & $66(94.3)$ & 0.024 \\
\hline BMI $\left(\mathrm{kg} / \mathrm{m}^{2}\right)^{\mathrm{b}}$ & $23.5 I \pm 2.90$ & $22.44 \pm 3.18$ & 0.006 \\
\hline Smoking history & $239(71.3)$ & 64 (91.4) & $<0.001$ \\
\hline \multicolumn{4}{|l|}{ Underlying disease } \\
\hline Hypertension & $172(5 \mid .3)$ & $34(48.6)$ & 0.673 \\
\hline Diabetes mellitus & $64(19.1)^{\prime}$ & $14(20.0)$ & 0.863 \\
\hline Tuberculosis & $37(11.0)$ & $4(5.7)$ & 0.179 \\
\hline Liver disease & $33(9.9)$ & $10(14.3)$ & 0.273 \\
\hline Heart disease & $46(13.7)$ & $9(12.9)$ & 0.846 \\
\hline Renal disease & $16(4.8)$ & $4(5.7)$ & $0.76 \mathrm{I}$ \\
\hline Neurologic disease & $37(11.0)$ & $10(14.3)$ & $0.44 I$ \\
\hline Malignancy & $158(47.2)$ & $47(67.1)$ & 0.002 \\
\hline ASA physical status & & & 0.998 \\
\hline 1 & $38(11.3)$ & $8(11.4)$ & \\
\hline 2 & $269(80.3)$ & $56(80.0)$ & \\
\hline 3 & $28(8.4)$ & $6(8.6)$ & \\
\hline \multicolumn{4}{|l|}{ PFT values } \\
\hline FVC, \% predicted ${ }^{b}$ & $103.64 \pm 15.86$ & $102.10 \pm 15.63$ & 0.461 \\
\hline $\mathrm{FEV}_{1}, \%$ predicted $^{\mathrm{c}}$ & $94(84-106)$ & $90(94.5-102.25)$ & 0.044 \\
\hline $\mathrm{FEV}_{1} / \mathrm{FVC}, \%^{\mathrm{c}}$ & $64(59-67)$ & $63(53.5-68)$ & 0.226 \\
\hline
\end{tabular}

Notes: Data are presented as numbers (\%) unless otherwise indicated. Median (range), ${ }^{b}$ mean $\pm \mathrm{SD},{ }^{\mathrm{c}}$ median (interquartile range).

Abbreviations: BMI, body mass index; ASA, American Society of Anesthesiologists; PFT, pulmonary function test; $\mathrm{FEV}_{1}$, forced expiratory volume in I second; FVC, forced vital capacity.

\section{Comparison between patients with and without postoperative complications}

On the basis of the univariate analysis, patients with postoperative complications were more likely to be male $(P=0.024)$, have lower BMI $(P=0.006)$, have history

Table 2 Types of postoperative complications

\begin{tabular}{lll}
\hline Category & Postoperative complication & n (\%) \\
\hline Pulmonary & & $20(4.9)$ \\
& Pneumonia & $1 \mathrm{I}(2.7)$ \\
& Pleural effusion & $9(2.2)$ \\
Infection & Atelectasis & $4(1.0)$ \\
& & $22(5.4)$ \\
& Organ specific infection & $19(4.7)$ \\
Renal & Bloodstream infection & $3(0.7)$ \\
& Septic shock & $1(0.2)$ \\
& & $6(1.5)$ \\
Cardiac & Acute kidney injury & $6(1.5)$ \\
& Dialysis & $2(0.5)$ \\
Wound & & $4(1.0)$ \\
& Arrhythmia & $4(1.0)$ \\
& & $27(6.7)$ \\
Others & Major & $17(4.2)$ \\
& Minor & $10(2.5)$ \\
& & $13(3.2)$ \\
& Acute urinary retention & $7(1.7)$ \\
& Delirium & $6(1.5)$ \\
\hline
\end{tabular}

Note: More than one postoperative complication could occur in each patient. of smoking $(P<0.001)$, and have lower $\mathrm{FEV}_{1}$ values $(P=0.044$; Table 1$)$. Thoracic surgery $(P=0.021)$ and upper abdominal surgery $(P<0.001)$ were significantly related to increased risk of postoperative complications. General anesthesia $(P<0.001)$, longer anesthesia time $(P<0.001)$, and a larger amount of EBL $(P<0.001)$ were also significantly related to postoperative complications (Table 3).

Patients with postoperative complications had a higher GOLD grade than those without complications $(P=0.020)$. However, the COPD GOLD group distribution according to the combined assessment did not show significant difference between patients with and without postoperative complications $(P=0.056)$. When patients were divided into two groups based on the risk evaluation, there was a significant association between the patients with a high risk (GOLD groups $\mathrm{C}$ or $\mathrm{D})$ and postoperative complications $(P=0.047)$, compared to those with a low risk (GOLD groups A or B). In contrast, the level of subjective dyspnea (GOLD groups A or $\mathrm{C}$ versus $\mathrm{B}$ or $\mathrm{D}$ ) was not related to the risk of postoperative complications ( $P>0.999$; Table 4$)$.

On the basis of multivariate analysis, we observed a significant association between postoperative complications and patients in high-risk group (GOLD groups $\mathrm{C}$ or $\mathrm{D}$; odds ratio $[\mathrm{OR}]=4.023,95 \%$ confidence interval $[\mathrm{CI}]=1.312-12.335, P=0.015)$. In addition, a larger amount of EBL (L) (OR $=1.788,95 \% \mathrm{CI}=1.076-2.972, P=0.025)$, and longer anesthesia time (hours) (OR $=1.445,95 \%$

Table 3 Surgical information of patients with and without complications

\begin{tabular}{|c|c|c|c|}
\hline Variables & $\begin{array}{l}\text { Patients without } \\
\text { postoperative } \\
\text { complications, } \\
n=335\end{array}$ & $\begin{array}{l}\text { Patients with } \\
\text { postoperative } \\
\text { complications, } \\
\mathrm{n}=70\end{array}$ & $P$-value \\
\hline \multicolumn{4}{|l|}{ Surgery site } \\
\hline Brain & $13(3.9)$ & $0(-)$ & 0.137 \\
\hline Head and neck & $44(13.1)$ & $3(4.3)$ & 0.036 \\
\hline Thorax & $8(2.4)$ & $6(8.6)$ & 0.021 \\
\hline Upper abdomen & $54(16.1)$ & $29(4 I .4)$ & $<0.001$ \\
\hline Lower abdomen & $36(10.7)$ & $9(12.9)$ & 0.675 \\
\hline Genitourinary & $94(28.1)$ & II (I5.7) & 0.032 \\
\hline Orthopedic & $45(13.4)$ & $7(10.0)$ & 0.435 \\
\hline General anesthesia & $268(80.0)$ & $69(98.6)$ & $<0.001$ \\
\hline $\begin{array}{l}\text { Emergency } \\
\text { operation }\end{array}$ & $7(2.1)$ & $0(-)$ & 0.610 \\
\hline $\begin{array}{l}\text { Anesthesia time } \\
\text { (hours) }\end{array}$ & $1.92(1.17-3.33)$ & $4.62(3.17-5.83)$ & $<0.001$ \\
\hline $\mathrm{EBL}(\mathrm{L})^{\mathrm{a}}$ & $0.02(0.00-0.15)$ & $0.40(0.15-0.96)$ & $<0.001$ \\
\hline
\end{tabular}

Notes: Data are presented as numbers (\%) unless otherwise indicated. ${ }^{a}$ Median (interquartile range).

Abbreviation: EBL, estimated blood loss. 
Table 4 Distribution of postoperative complications based on the COPD group

\begin{tabular}{|c|c|c|c|}
\hline Comparison & $\begin{array}{l}\text { Patients without } \\
\text { complications, } n=335\end{array}$ & $\begin{array}{l}\text { Patients with } \\
\text { complications, } n=70\end{array}$ & $P$-value \\
\hline GOLD grade ${ }^{a}$ & & & 0.020 \\
\hline 1 & $272(8 \mid .2)$ & $48(68.6)$ & \\
\hline 2 & $54(16.1)$ & $17(24.3)$ & \\
\hline 3 & $9(2.7)$ & $4(5.7)$ & \\
\hline 4 & $0(-)$ & I (I.4) & \\
\hline GOLD group & & & 0.056 \\
\hline$A$ & $210(62.7)$ & $4 \mathrm{I}(58.6)$ & \\
\hline B & $110(32.8)$ & $20(28.6)$ & \\
\hline C & $7(2.1)$ & $4(5.7)$ & \\
\hline $\mathrm{D}$ & $8(2.4)$ & $5(7.1)$ & \\
\hline Risk assessment & & & 0.047 \\
\hline Low risk (A or $B)$ & $319(95.2)$ & $62(88.6)$ & \\
\hline High risk (C or $\mathrm{D})$ & $16(4.8)$ & $8(11.4)$ & \\
\hline Level of symptoms & & & $>0.999$ \\
\hline Less symptoms ( $\mathrm{A}$ or $\mathrm{C})$ & $217(64.8)$ & $45(64.3)$ & \\
\hline More symptoms (B or $\mathrm{D})$ & $118(35.2)$ & $25(35.7)$ & \\
\hline
\end{tabular}

Notes: Data are presented as numbers (\%). ${ }^{\mathrm{a} G O L D}$ grade is defined as: I, FEV,$\geq 80 \%$ predicted; $2,50 \% \leq \mathrm{FEV},<80 \%$ predicted; $3,30 \% \leq \mathrm{FEV}$, $<50 \%$ predicted; 4 , FEV $<30 \%$ predicted.

Abbreviations: COPD, chronic obstructive pulmonary disease; GOLD, Global Initiative for Chronic Obstructive Lung Disease.

$\mathrm{CI}=1.205-1.732, P<0.001)$ were related to postoperative complications (Table 5).

\section{Postoperative complications analysis}

We analyzed each type of postoperative complications to evaluate if the GOLD group was significantly associated with any particular one.

Higher-risk group (GOLD groups C or D) was significantly associated with postoperative infection $(\mathrm{OR}=3.755$, $95 \% \mathrm{CI}=1.053-13.387, P=0.041)$ or wound complications (OR $=5.883,95 \% \mathrm{CI}=1.642-21.082, P=0.007$ ) compared to a lower-risk group (GOLD groups A or B) based on multivariate binary logistic regression analysis. On the other hand, higher-risk group was not significantly associated with postoperative pulmonary complications (OR $=1.103$, 95\% $\mathrm{CI}=0.187-6.510, P=0.914)$.

Table 5 Multivariable analysis for factors related to postoperative complications

\begin{tabular}{llll}
\hline Variables & OR & $\mathbf{9 5 \% ~ C I ~}$ & P-value \\
\hline High-risk group ${ }^{\mathrm{a}}$ & 4.023 & $\mathrm{I} .3 \mathrm{I} 2-\mathrm{I} 2.335$ & $0.0 \mathrm{I} 5$ \\
Male sex & 0.620 & $0.134-2.87 \mathrm{I}$ & $0.54 \mathrm{I}$ \\
$\mathrm{BMI}\left(\mathrm{kg} / \mathrm{m}^{2}\right)$ & 0.962 & $0.864-\mathrm{I} .072$ & 0.484 \\
Smoking history & 6.079 & $\mathrm{I} .704-2 \mathrm{I} .687$ & 0.005 \\
Underlying malignancy & $\mathrm{I} . \mathrm{II} 2$ & $0.552-2.243$ & 0.766 \\
Thoracic surgery & 2.069 & $0.555-7.7 \mathrm{I} 4$ & 0.279 \\
Upper abdominal surgery & $\mathrm{I} .883$ & $0.927-3.827$ & 0.080 \\
Estimated blood loss (L) & $\mathrm{I} .788$ & $\mathrm{I} .076-2.972$ & 0.025 \\
General anesthesia & 4.547 & $0.566-36.54 \mathrm{I}$ & 0.154 \\
Anesthesia time (hours) & $\mathrm{I} .445$ & $\mathrm{I} .205-\mathrm{I} .732$ & $<0.00 \mathrm{I}$ \\
\hline
\end{tabular}

Note: ${ }^{\mathrm{a}} \mathrm{GOLD}$ groups $\mathrm{C}$ or $\mathrm{D}$.

Abbreviations: OR, odds ratio; $\mathrm{Cl}$, confidence interval; $\mathrm{BMI}$, body mass index; GOLD, Global Initiative for Chronic Obstructive Lung Disease.
Upper abdominal surgery and a larger amount of EBL during surgery were related to an increased risk of postoperative pulmonary complications, while lower BMI and larger EBL were related to increased risk of postoperative infection. Larger EBL, smoking history, and upper abdominal surgery increased the risk of wound complications in COPD patients in high-risk group (Table S1).

\section{Discussion}

Of the 405 COPD patients who underwent surgery, 70 patients $(17.3 \%)$ experienced postoperative complications, similar to those previously reported, ${ }^{5,10,11}$ High-risk GOLD groups (GOLD groups C or D) were significantly associated with postoperative complications, as compared to low-risk GOLD groups (GOLD groups A or B). Most common postoperative problems included infection, wound, and pulmonary complications.

Because of the increased life expectancy associated with various comorbidities, surgeons, anesthesiologists, and respiratory physicians need to deal with large numbers of high-risk respiratory patients. COPD is considered as an independent risk factor for postoperative mortality and cardiopulmonary complications. ${ }^{12}$ It is now believed that COPD is also a risk factor for various postoperative morbidities, such as stroke, acute kidney injury, ascites, and wound dehiscence, in cardiopulmonary surgery, as well as genitourinary, orthopedic, plastic surgery, and others. ${ }^{5}$

In this study, the high-risk GOLD groups (GOLD groups $\mathrm{C}$ or D) and postoperative complications were significantly associated. The level of airflow limitation ( $\mathrm{FEV}_{1} \%$ predicted) 
had a significant influence on postoperative complications; this was compatible with previous findings that severe airflow limitation leads to increased risk of postoperative respiratory complications after upper abdominal and thoracic surgery. ${ }^{13-15}$

On the other hand, severe dyspnea (GOLD groups B or D) was not related to postoperative complications. We further analyzed the results based on mMRC and CAT scores because classification of the patients could differ depending on the scoring system used (Table S2), given that the mMRC is a one-dimensional measurement for quantifying dyspnea only, while the CAT score is a multidimensional method that assesses eight categories. ${ }^{16}$ Neither the mMRC nor the CAT scores showed a significant relationship between postoperative complications.

Very few reports are available about the relationship between the level of dyspnea and postoperative complications. A previous study of 269 COPD patients undergoing total aortic arch replacement showed that the patient's subjective dyspnea was significantly related to postoperative pulmonary complications. ${ }^{17}$ However, this report only included aortic arch replacement surgery and related pulmonary complications, which differs from our study.

In addition to the high-risk GOLD groups (GOLD groups $\mathrm{C}$ or D), male sex, lower BMI, underlying malignancy, thoracic and upper abdominal surgery, general anesthesia, longer anesthesia time, and a larger EBL during surgery were also related to an increased risk of postoperative complications. A lower BMI represents a poor nutritional status, which could affect postoperative outcomes. ${ }^{18,19}$ Thoracic and upper abdominal surgeries, longer anesthesia time, and general anesthesia have previously been reported to be related to postoperative complications. ${ }^{12,17,20}$ Anesthetic agents and muscle relaxants, as well as mechanical ventilation during general anesthesia, interfere with the respiratory system and therefore affect postoperative recovery. ${ }^{12}$

In our study, age was not related to postoperative morbidities. Several previous studies have shown advanced age as a risk factor for selected types of complications in limited circumstances. ${ }^{21,22}$ However, opposite results do exist suggesting that advanced age is not directly related to, or even protective against postoperative events. ${ }^{23,24}$ The aforementioned studies were based on specific types of surgeries and complications, which lack various postoperative morbidities such as wound dehiscence, renal failure, delirium, and so on. Our study focused on a variety of surgery types and postoperative events, which leads to the current result that age has no significant impact on all-cause postoperative complications.
We also analyzed the variables for each type of postoperative complication. High-risk groups (GOLD groups C or D) were significantly associated with an increased risk of postoperative infection and wound complications. COPD patients have lower partial pressure of oxygen in arterial blood than non-COPD patients as reported in our previous study. ${ }^{6}$ Such limited oxygen within the healing tissues leads to impaired wound healing, susceptibility to bacterial infections, and dehiscence of surgical anastomosis. This is also exacerbated by the antiproliferative effects of nicotine on red blood cells, fibroblasts, and macrophages in smokers with COPD. ${ }^{12,25}$ Decreased oxygen delivery can also delay woundhealing processes such as re-epithelialization as proven in animal studies. ${ }^{26}$ A previous study of patients undergoing abdominal surgery reported that the major independent risk factors for wound dehiscence include chronic pulmonary disease and postoperative coughing, which can lead to delayed wound healing due to the mechanical movement at the site of surgery. ${ }^{27}$

To the best of our knowledge, this is the first study evaluating the relationship between the COPD GOLD group and postoperative complications. However, this study had several limitations. First, this is a retrospective study performed at a single center. Second, the small number of patients in GOLD groups $\mathrm{C}$ and $\mathrm{D}$ affected the statistical power of the comparisons in this study. GOLD groups A and B comprised 251 and 130 patients each, while GOLD groups C and D comprised only eleven and 13 patients, respectively. Third, study population was outpatient based, with relatively good performance status; therefore, caution is needed to generalize this result on other populations.

\section{Conclusion}

In conclusion, $17.3 \%$ of COPD patients experienced postoperative complications. Using the GOLD definition, highrisk groups (GOLD groups $\mathrm{C}$ or D) were more significantly associated with postoperative complications than low-risk groups (GOLD groups A or B). While the severity of dyspnea does not show significant correlation with postoperative complications, lower value of $\mathrm{FEV}_{1}$ has much influence on increased risk of surgical complications.

\section{Author contributions}

SMC and HJK contributed to conception and design of the study, and acquisition, and analysis of data. JL, YSP, CHL, SML, JJY, CGY, YWK, and SKH contributed to study design and interpretation of data. SMC and HJK drafted the manuscript. JL, YSP, CHL, SML, JJY, CGY, YWK, and SKH revised the manuscript. All authors had access 
to the final version of the manuscript, and approved the version to be published. All authors agree to be accountable for all aspects of the work in ensuring that questions related to the accuracy or integrity of any part of the work are appropriately investigated and resolved.

\section{Disclosure}

The authors report no conflicts of interest in this work.

\section{References}

1. Nazir SA, Erbland ML. Chronic obstructive pulmonary disease: an update on diagnosis and management issues in older adults. Drugs Aging. 2009;26(10):813-831.

2. Chen CZ, Ou CY, Yu CH, Yang SC, Chang HY, Hsiue TR. Comparison of global initiative for chronic obstructive pulmonary disease 2013 classification and body mass index, airflow obstruction, dyspnea, and exacerbations index in predicting mortality and exacerbations in elderly adults with chronic obstructive pulmonary disease. J Am Geriatr Soc. 2015;63(2):244-250.

3. LeivsethL, Brumpton BM, Nilsen TI, MaiXM, Johnsen R, Langhammer A. GOLD classifications and mortality in chronic obstructive pulmonary disease: the HUNT Study, Norway. Thorax. 2013;68(10):914-921.

4. Lange P, Marott JL, Vestbo J, et al. Prediction of the clinical course of chronic obstructive pulmonary disease, using the new GOLD classification: a study of the general population. Am J Respir Crit Care Med. 2012;186(10):975-981.

5. Gupta H, Ramanan B, Gupta PK, et al. Impact of COPD on postoperative outcomes: results from a national database. Chest. 2013;143(6): 1599-1606.

6. Choi SM, Lee J, Park YS, et al. Prevalence and global initiative for chronic obstructive lung disease group distribution of chronic obstructive pulmonary disease detected by preoperative pulmonary function test. PLoS One. 2015;10(1):e0115787.

7. Dindo D, Demartines N, Clavien P-A. Classification of surgical complications: a new proposal with evaluation in a cohort of 6336 patients and results of a survey. Ann Surg. 2004;240(2):205-213.

8. Mandell LA, Wunderink RG, Anzueto A, et al. Infectious Diseases Society of America/American Thoracic Society consensus guidelines on the management of community-acquired pneumonia in adults. Clin Infect Dis. 2007;44(Suppl 2):S27-S72.

9. Bello S, Minchole E, Fandos S, et al. Inflammatory response in mixed viral-bacterial community-acquired pneumonia. BMC Pulm Med. 2014;14:123.

10. Hausman MS Jr, Jewell ES, Engoren M. Regional versus general anesthesia in surgical patients with chronic obstructive pulmonary disease: does avoiding general anesthesia reduce the risk of postoperative complications? Anesth Analg. 2015;120(6):1405-1412.

11. Manganas H, Lacasse Y, Bourgeois S, Perron J, Dagenais F, Maltais F. Postoperative outcome after coronary artery bypass grafting in chronic obstructive pulmonary disease. Can Respir J. 2007;14(1):19-24.
12. Licker M, Schweizer A, Ellenberger C, Tschopp JM, Diaper J, Clergue F. Perioperative medical management of patients with COPD. Int JChron Obstruct Pulmon Dis. 2007;2(4):493-515.

13. Barisione G, Rovida S, Gazzaniga GM, Fontana L. Upper abdominal surgery: does a lung function test exist to predict early severe postoperative respiratory complications? Eur Respir J. 1997;10(6):1301-1308.

14. Linden PA, Bueno R, Colson YL, et al. Lung resection in patients with preoperative $\mathrm{FEV}_{1}<35 \%$ predicted. Chest. 2005;127(6):1984-1990.

15. Money SR, Rice K, Crockett D, et al. Risk of respiratory failure after repair of thoracoabdominal aortic aneurysms. Am J Surg. 1994; 168(2):152-155.

16. Kim S, Oh J, Kim YI, et al. Differences in classification of COPD group using COPD assessment test (CAT) or modified Medical Research Council (mMRC) dyspnea scores: a cross-sectional analyses. BMC Pulm Med. 2013;13:35.

17. Miyahara S, Nakai H, Izawa N, et al. Influences of chronic obstructive pulmonary disease on outcomes of total arch replacement. Ann Thorac Surg. 2015;99(1):72-78.

18. Barnes PJ, Celli BR. Systemic manifestations and comorbidities of COPD. Eur Respir J. 2009;33(5):1165-1185.

19. Prescott E, Almdal T, Mikkelsen KL, Tofteng CL, Vestbo J, Lange P. Prognostic value of weight change in chronic obstructive pulmonary disease: results from the Copenhagen City Heart Study. Eur Respir J. 2002;20(3):539-544.

20. Tang H, Zhu J, Ji F, Wang S, Xie Y, Fei H. Risk factors for postoperative complication after spinal fusion and instrumentation in degenerative lumbar scoliosis patients. J Orthop Surg Res. 2014;9(1):15.

21. Polanczyk CA, Marcantonio E, Goldman L, et al. Impact of age on perioperative complications and length of stay in patients undergoing noncardiac surgery. Ann Intern Med. 2001;134(8):637-643.

22. Panaich SS, Badheka AO, Chothani A, et al. Results of ventricular septal myectomy and hypertrophic cardiomyopathy (from Nationwide Inpatient Sample [1998-2010]). Am J Cardiol. 2014;114(9):1390-1395.

23. Catanzarite T, Rambachan A, MuellerMG, PileckiMA, Kim JY, Kenton K. Risk factors for 30-day perioperative complications after Le Fort colpocleisis. J Urol. 2014;192(3):788-792.

24. Ravi B, Croxford R, Austin PC, et al. Increased surgeon experience with rheumatoid arthritis reduces the risk of complications following total joint arthroplasty. Arthritis Rheumatol. 2014;66(3):488-496.

25. Spiliotis J, Tsiveriotis K, Datsis AD, et al. Wound dehiscence: is still a problem in the 21th century: a retrospective study. World J Emerg Surg. 2009;4:12.

26. Sano H, Ichioka S, Sekiya N. Influence of oxygen on wound healing dynamics: assessment in a novel wound mouse model under a variable oxygen environment. PLoS One. 2012;7(11):e50212.

27. van Ramshorst GH, Nieuwenhuizen J, Hop WC, et al. Abdominal wound dehiscence in adults: development and validation of a risk model. World J Surg. 2010;34(1):20-27. 


\section{Supplementary materials}

Table SI Multivariate analysis of postoperative pulmonary complications, infection, and wound complications

\begin{tabular}{|c|c|c|c|}
\hline Variables & OR & $95 \% \mathrm{Cl}$ & $P$-value \\
\hline \multicolumn{4}{|c|}{ Postoperative pulmonary complication ${ }^{\mathrm{a}}$} \\
\hline High-risk group ${ }^{\mathrm{b}}$ & 1.103 & $0.187-6.510$ & 0.914 \\
\hline Upper abdominal surgery & 3.155 & $1.208-8.238$ & 0.019 \\
\hline $\mathrm{EBL}(\mathrm{L})$ & 1.591 & $1.05 I-2.409$ & 0.028 \\
\hline \multicolumn{4}{|l|}{ Postoperative infection ${ }^{c}$} \\
\hline High-risk group ${ }^{\mathrm{b}}$ & 3.755 & $1.053-13.387$ & 0.041 \\
\hline BMI $\left(\mathrm{kg} / \mathrm{m}^{2}\right)$ & 0.847 & $0.727-0.987$ & 0.034 \\
\hline EBL (L) & 1.909 & $1.285-2.836$ & 0.001 \\
\hline \multicolumn{4}{|c|}{ Postoperative wound complication ${ }^{d}$} \\
\hline High-risk group ${ }^{b}$ & 5.883 & $1.642-21.082$ & 0.007 \\
\hline $\mathrm{EBL}(\mathrm{L})$ & 1.593 & $1.014-2.503$ & 0.043 \\
\hline Smoking history & 11.532 & $1.393-95.472$ & 0.023 \\
\hline Upper abdominal surgery & 3.846 & $1.607-9.209$ & 0.002 \\
\hline
\end{tabular}

Notes: ${ }^{a} \mathrm{Adj}$ justed for underlying heart disease, underlying malignancy, upper abdominal surgery, EBL, and general anesthesia; ${ }^{\mathrm{b}} \mathrm{GOLD}$ groups $\mathrm{C}$ and $\mathrm{D}$; $\mathrm{c}_{\mathrm{adjusted}}$ for BMI, underlying malignancy, upper abdominal surgery, EBL, and general anesthesia; dadjusted for BMI, underlying malignancy, smoking history, upper abdominal surgery, EBL, and general anesthesia.

Abbreviations: $\mathrm{OR}$, odds ratio; $\mathrm{Cl}$, confidence interval; $\mathrm{BMI}$, body mass index; $\mathrm{EBL}$, estimated blood loss.

Table S2 Relationship between dyspnea and postoperative complications

\begin{tabular}{cll}
\hline $\begin{array}{l}\text { Symptom } \\
\text { assessment }\end{array}$ & $\begin{array}{l}\text { Patients without postoperative } \\
\text { complications, } \mathbf{n}=\mathbf{3 3 5}\end{array}$ & $\begin{array}{l}\text { Patients with postoperative } \\
\text { complications, } \mathbf{n}=\mathbf{7 0}\end{array}$ \\
\hline $\begin{array}{l}\text { mMRC } \\
<2\end{array}$ & $278(83.0)$ & $60(85.7)$ \\
$\geq 2$ & $57(17.0)$ & $10(14.3)$ \\
CAT & & \\
$<10$ & $238(71.0)$ & $49(70.0)$ \\
$\geq 10$ & $97(29.0)$ & $21(30.0)$ \\
\hline
\end{tabular}

Note: Data are presented as numbers (\%).

Abbreviations: mMRC, modified medical research scale; CAT, COPD assessment test.

\section{Publish your work in this journal}

The International Journal of COPD is an international, peer-reviewed journal of therapeutics and pharmacology focusing on concise rapid reporting of clinical studies and reviews in COPD. Special focus is given to the pathophysiological processes underlying the disease, intervention programs, patient focused education, and self management protocols.

\section{Dovepress}

This journal is indexed on PubMed Central, MedLine and CAS. The manuscript management system is completely online and includes a very quick and fair peer-review system, which is all easy to use. Visit $\mathrm{http}: / / \mathrm{www}$. dovepress.com/testimonials.php to read real quotes from published authors. 